\title{
Optimization design of effective management model of large construction project
}

\author{
LIU Xiao-li
}

(Jinan Engineering Vocational Technical College, Shandong,Jinan,250200)

\begin{abstract}
Keywords: construction project; project management; mathematical model;
\end{abstract}
\begin{abstract}
: in the management process of large construction projects, the related factors and the influenced parameters are various. A mathematical model of construction project management is complex, it is difficult to form effective project management measures. In the traditional architectural engineering project management model using the multiple linear regression model, the feature fusion result of construction projects is not ideal, it is difficult to form an effective management model. For this, a mathematical modeling method for management model of large scale construction project based on fuzzy assignment and rough set algorithm is proposed. Firstly, the parameters model affected construction project management is analyzed, to establish the project management system.

Then, the analysis of large scale construction project and related influencing factor is the linear phase relationship, to get the mathematical model of rough set coupling characteristics in construction project. Finally, using fuzzy assignment and rough set algorithm achieve the improvement of the management mathematical model. Simulation results show that, using the proposed model for efficient management of construction engineering project, has good management performance, showing a good application value.
\end{abstract}

\section{1 introduction}

Current China is in a hot time with vigorously development of the construction industry and real estate, construction enterprises are just unfolding, and building industry has been expanded [1-3]. At the same time, research on the management of large-scale construction engineering project is a key and hot research topic. Because the construction project resource and scheduling is very complicated, how to make this part of the resources allocation better, is the core problem to research [4-6], and has become a hot research on the development of construction industry of modern architecture. Research of management model of construction project [7], and the establishment of a set of effective management system for large scale construction project, has important practical significance in the field of today's construction industry management, thus, the related model and algorithm research, have attracted people's close attention [8].

\section{2 the whole building of project management model for large scale construction engineering}

In the construction of the overall model of large scale construction project management, the multiple linear regression mathematical model is commonly used in traditional method resulting in not ideal feature fusion result of construction project. In this paper, according to the construction environment and requirements of the construction production, reasonable resources allocation of construction project is performed. The establishment of large scale construction engineering project management model can improve the rationality of construction project management to a certain extent.

In the process of management data analysis of large scale construction engineering project, through the information service agent system access and resource sharing, resource management scheduling of construction project can be implemented. Here, it needs to establish a mathematical model, and the analysis of construction engineering and related influencing factor is the linear phase relation, so as to realize the reasonable taking and matching of the building project and human resources. The required resources of building project are assigned to relevant projects to work, and 
the ultimate goal is to maximize the use of maneuverable personnel and equipment resources, to get building project management mathematical model established as follows:

$$
\begin{aligned}
& \max Z=\sum_{i=1}^{m} \sum_{j=1}^{m} x_{i j} c_{i j} \\
& s t=\sum_{j=1}^{m} x_{i j} \\
& s t=\sum_{i=1}^{m} x_{i j} \\
& x_{i j}=1 \\
& s t=0, \text { or }, 1
\end{aligned}
$$

Among them, $x_{i j}=1$ represents the building project resources used reasonably, and it is designed as green signal early warning, $x_{i j}=0$ represents that the rational utilization of building project resources is reluctant, setting to orange signal early warning, $x_{i j}=-1$ indicate the building project resources cannot be used, setting to red signal early warning, thus realizing the overall construction of large-scale construction engineering project management model.

\section{3 the related principle of establishing effective management model of large scale construction project}

3.1 data sources

This paper takes some large scale construction project data in Beijing as data source to study. The department in charge of the project has started to clear up the related data of project, and has completed initially the modeling of large scale construction project management. In this study, in the process of large scale construction project management, the related human resources and equipment resources in the construction projects are focused on to research, to achieve the rational allocation of the construction project resources.

3.2 research variables

For the effective management of large scale construction project, the completion ratio of large scale construction engineering project is set as dependent variable $\mathrm{y}$, the human resource $\mathrm{x} 1$ of construction engineering project, the proportion $\mathrm{x} 2$ of construction project needed funds accounted for the total funds of the company, and the total number of construction engineering equipment $\mathrm{x} 3$ are as the independent variables.

3.3 description of the mathematical model

The classical prediction model is applied in this paper to calculate the total capital need to invest in large scale construction project, the formula is as follows:

$$
C_{\mathrm{i}}=\left(C_{0}+D_{i} e^{-\omega T_{\mathrm{i}}}\right) N\left(t_{1}\right)+L e^{-\omega T_{\mathrm{i}}} N\left(t_{2}\right)
$$

Among them, $\mathrm{t}=1,2, \ldots . . \mathrm{N}$.

In the above formula, $\mathrm{t}$ is the time variable, $\mathrm{C} 0$ the raised total capital for establishing project management department of large scale construction engineering, $\mathrm{L}$ is the of management cost construction engineering project, $\mathrm{T}$ is the cash conversion cycle, the number of equipment $\omega$ in building operations process is defined as a constant. in this study, assuming that the project schedule can be maintained by project management unit of the large-scale construction engineering in a reasonable range, that is to say, the total project cycle $\omega$ can be assumed as the constant 1 year. The variables $d_{1}$ and $d_{1}$ are expressed by the following formula.

$$
d_{1}=\frac{\ln \frac{C_{0}}{L}+\left(\omega+0.5^{*} \sigma^{2}\right) T}{\sigma^{*} \sqrt{T}}
$$


$d_{2}=\frac{\ln \frac{C_{0}}{L}+\left(\omega-0.5^{*} \sigma^{2}\right) T}{\sigma^{*} \sqrt{T}}=d_{1}-\sigma \sqrt{T}$

Among them, the annual variance $\sigma 2$ is assumed to be constant. After calculating the construction progress during different construction period, the corresponding costs or expenses can be calculated in accordance with the used equipment and personnel quantity in large scale construction projects, so as to get the corresponding amortised cost or expense and are included in assets table respectively. Then, the corresponding total investment, turnover of total capital, asset liability ratio and the expected income is calculated. The form of the model is as follows:

$$
\mathrm{y}_{i}=x_{i} \beta_{i}+\mu_{i}
$$

Thereinto, $i=1,2, \ldots, N$ 。

In the above formula, the dependent variable $y_{i}$ is the total investment in construction process of a large scale construction project. $x_{i}$ is a $\mathrm{k} x 1$ dimensional independent variable, $\beta_{\mathrm{i}}$ is the independent variable coefficient matrix, $\mu_{\mathrm{i}}$ is the error term of independent random variables. The above formula can be written as the regression form of matrix:

$$
\left(\begin{array}{c}
\mathrm{y}_{1} \\
y_{2} \\
\vdots \\
y_{N}
\end{array}\right)=\left(\begin{array}{cccc}
x_{1} & 0 & \cdots & 0 \\
0 & x_{2} & \ddots & \vdots \\
\vdots & \ddots & \ddots & 0 \\
0 & \cdots & 0 & x_{N}
\end{array}\right)\left(\begin{array}{c}
\beta_{1} \\
\beta_{2} \\
\vdots \\
\beta_{N}
\end{array}\right)+\left(\begin{array}{c}
\mu_{1} \\
\mu_{2} \\
\vdots \\
\mu_{N}
\end{array}\right)
$$

Setting:

$$
\begin{aligned}
W_{x x, i} & =\sum\left(x_{i t}-\overline{x_{i}}\right)\left(x_{i t}-\overline{x_{i}}\right)^{\prime} \\
W_{x y, i} & =\sum\left(x_{i t}-\overline{x_{i}}\right)^{\prime}\left(y_{i t}-\overline{y_{i}}\right) \\
W_{y y, i} & =\sum\left(y_{i t}-\overline{y_{i}}\right)^{2}
\end{aligned}
$$

The residual error square calculation formula of large scale construction engineering project management model is as follows:

$$
S=W_{y y}-W_{x y}^{\prime} W_{x x}^{-1} W_{x y}
$$

\section{4 simulation experiments and results analysis}

In order to verify the performance of large scale construction project management model proposed in this paper, simulation experiment is performed. the resource scheduler in GridSim simulation platform is made EFRB expansion, and one hundrad building project tasks are constructed to compose a resource scheduling set.

In the process of the experiment, the satisfaction of construction engineering management is analyzed, with cumulative contribution rate for the test index, to make simulation experiment, and obtain the results as shown in the figure below. It can be seen from the figure below, the cumulative contribution rate of satisfaction testing by using the proposed model is $66 \%$, indicating the cumulative contribution rate is relatively high, and the proposed model has better benefit of large scale construction project management. 


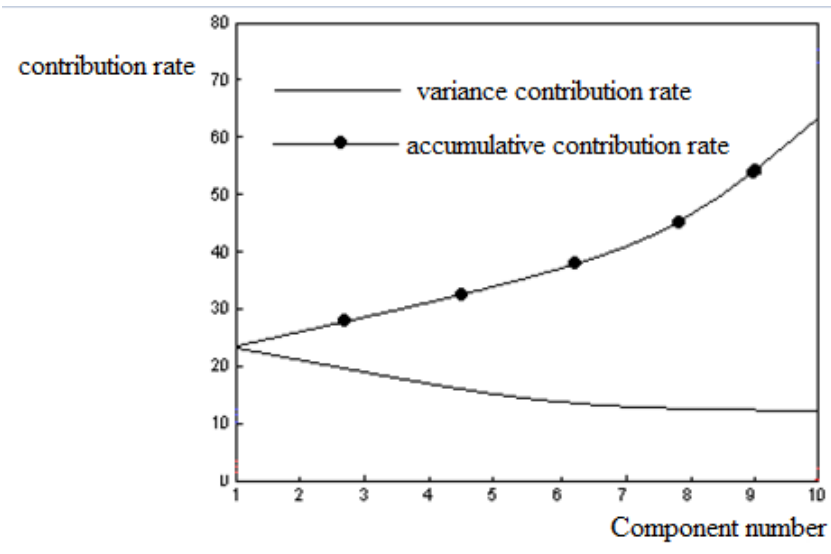

Figure 1 the trend of contribution rate of construction engineering project management

The next step of the simulation experiment is the analysis of the cost in the process of construction project management. the construction cost of 10 months are selected as the basic data, in which, the data of the first 5 months are as a group of experimental data, and which are managed by using the proposed management model of construction project; the data of the next 5 months are as a group of comparison data, managed by using the traditional way. The obtained index of construction cost by using the proposed model as shown below. It can be seen from the figure below, using the proposed model, can effectively reduce the construction cost of the construction project management process. Through the efficient management, the construction cost is greatly reduced, showing the superior application performance of the proposed model.

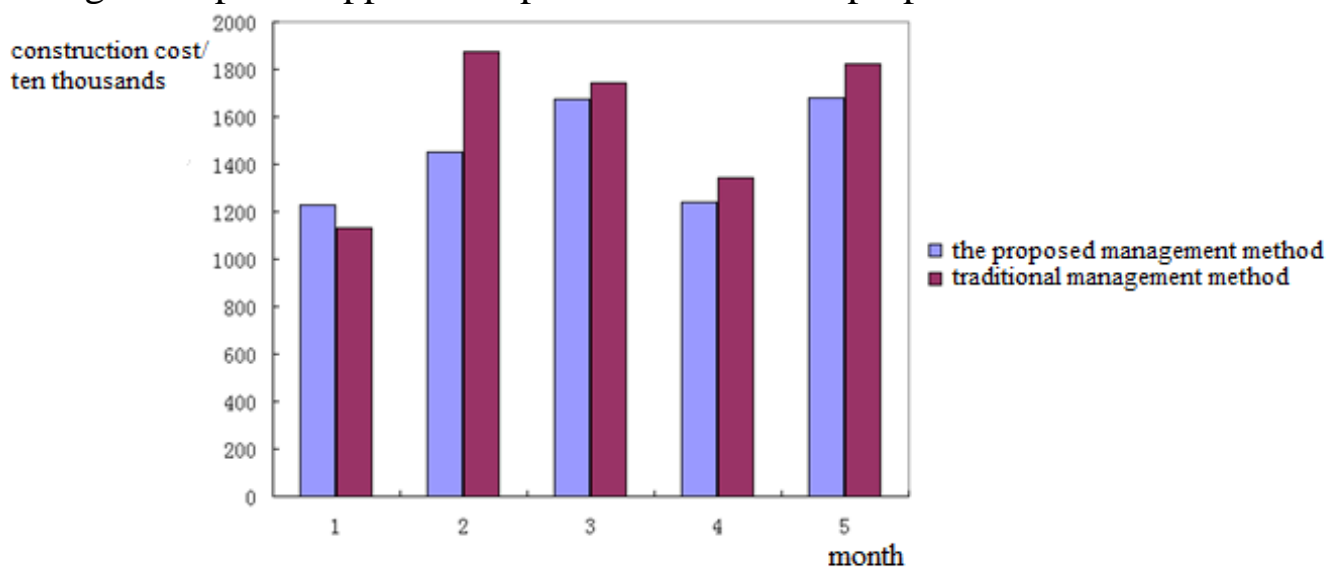

Figure 2 Construction cost of construction engineering project

\section{Conclusion}

For the defects of complex mathematical modeling of project management and too difficult to form effective project management measures caused by much more related factors and influenced parameters, in the process of large scale construction engineering projects management, a mathematical modeling method for management model of large scale construction project based on fuzzy assignment and rough set algorithm is proposed. Firstly, the parameters model affected construction project management is analyzed, to establish the project management system.

Then, the analysis of large scale construction project and related influencing factor is the linear phase relationship, to get the mathematical model of rough set coupling characteristics in construction project. Finally, using fuzzy assignment and rough set algorithm achieve the improvement of the management mathematical model. Simulation results show that, using the proposed model for efficient management of construction engineering project, has good management performance, showing a good application value. 


\section{References}

[1] Zhang Huali. Application of chain-pole equilibrium model to constructions management [J]. Journal of Chang'an University: Natural Science Edition, 2013, (6): 66-69.

[2] Sun Hongli, Yu Qingjian. The Practice of System Management based on 3D Construction Information Model in Construction of Projects [J]. Southern Power System technology, 2009:221-225.

[3] Zhu Guangjun, Yao Lin, Cong Jinsong. Research on the model of construction project management and organizational maturity [J]. Modernization of management, 2006, (3): 58-61.

[4] Shen Liangfeng. A New Model of Celerity Estimation on Cost of Architectural Engineering and Its Application [J]. Industrial engineering and management, 2004, 9 (6): 83-85.

[5] LAN Xiaochun, Zhang Lijun. Construction Project Operation Evaluating Tenders Model and Its Implementation [J]. Journal of Harbin University of Science and Technology, 2004, 9 (1): 88-90.

[6] Fu Lijuan. Research on safety management models in architectural construction [J]. Shanxi architecture, 2012, 38 (6): 275-277.

[7] Li Hailing, Liu Kejian. Research on the Development of Management Model for Construction Project Group [J]. Journal of Xihua University: Natural Science Edition, 2011, 30 (2): 88-91.

[8] Zhao Hong. The Study on the Models and Methods of Project Multidimensional Cost Management in Building Construction Enterprises [J]. Scientific decision-making, 2009, (6): 72-80. 